Edisi Januari - Juni 2020 Vol 19 No 1

\section{JURNAL ILMU PEMERINTAHAN}

\section{nakhoda}

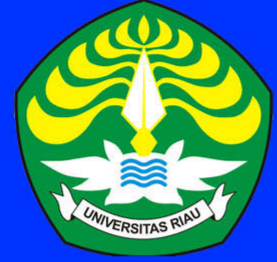

Innovation Hub: Media Kolaborasi Menuju Pemerintahan Daerah Inovatif Herie Saksono

Institusional Building dalam Mengatasi Persoalan Pertambangan Emas Tanpa Izin Di Kabupaten Kuantan Singingi Provinsi Riau

Khotami

Gerakan Masyarakat Tertib Administrasi Kependudukan Melalui Inovasi Pelayanan Lukadesi (Keluarga Berduka Desa Siaga)

Di Kabupaten Sleman D.I Yogyakarta

Hendy Setiawan, Fariza Ikhsanditya

Provinsi 'Istimewa Melayu Riau Kepulauan'

Muchid Albintani, Auradian Marta

Kaderisasi dan Penetapan Calon Legislatif pada Partai Politik (Studi DPD Partai Nasional Demokrat Seram Bagian Barat 2019)

Fandi Ahmad Sintani, Wahab Tuanaya, Marno Wance

Factors of Affect Deliberation of Maguwoharjo

Village Development Planing Sub-District Depok Regency Sleman Yogyakarta Muhammad Rafi, Ulung Pribadi, Fajar Rahmanto

Survey Kepuasan Masyarakat (SKM) pada Badan PendapatanDaerah Kabupaten Bintan

Suherry, Billy Jenawi, Rendra Setyadiharja,

Zamzami A Karim, Firman Setyawan, Rany Angraini

Peran Dewan Perwakilan Daerah (DPD) dalam

Pembentukan Daerah Otonomi Baru (DOB) Di wilayah Provinsi Maluku Utara

Abdul Halil Ibrahim, Bakri La Suhu, Rifjal Tifandy, Marno Wance

MEDIA INFORMASI DAN KOMUNIKASI ILMIAH CIVITAS AKADEMIKA JURUSAN ILMU PEMERINTAHAN

FAKULTAS ILMU SOSIAL DAN ILMU POLITIK

UNIVERSITAS RIAU
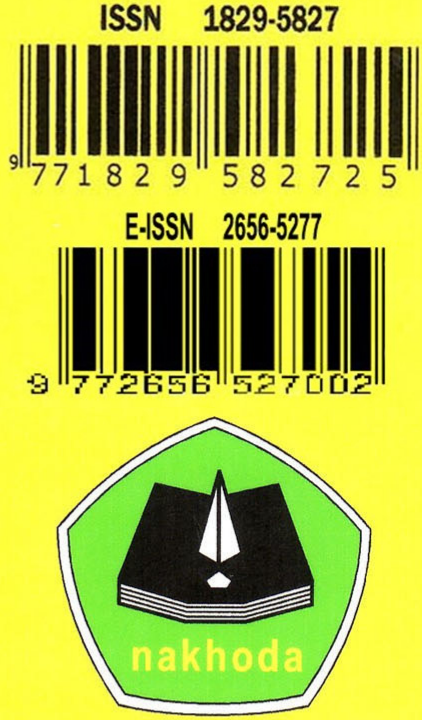

DITERBITKAN OLEH :

LABORATORIUM ILMU PEMERINTAHAN
SEKRETARIAT :

KAMPUS BINA WIDYA SIMPANG BARU

PANAM KM. 12,5 PEKANBARU

(28293) Telp/Fax. (0761)63277 
NAKHODA:

JURNAL

ILMU PEMERINTAHAN
NAKHODA: JURNAL ILMU PEMERINTAHAN

Edisi Januari - Juni 2020 Volume: 19 Nomor: 1

ISSN : 1829-5827 | E-ISSN : 2656-5277

DOI : https://doi.org/10.35967/jipn

https://nakhoda.ejournal.unri.ac.id/index.php/JIPN

INNOVATION HUB: MEDIA KOLABORASI MENUJU PEMERINTAHAN DAERAH INOVATIF

Herie Saksono

Badan Penelitian dan Pengembangan (BPP) Kementerian Dalam Negeri, Jakarta, Indonesia

$1-16$

INSTITUTION BUILDING DALAM MENGATASI PERSOALAN PERTAMBANGAN EMAS

TANPA IZIN DI KABUPATEN KUANTAN SINGINGI PROVINSI RIAU

Khotami

Program Studi Ilmu Pemerintahan, Fakultas IImu Sosial dan IImu Politik Universitas Islam Riau. 17 - 37

Pekanbaru-Indonesia

GERAKAN MASYARAKAT TERTIB ADMINISTRASI KEPENDUDUKAN MELALUI INOVASI

PELAYANAN LUKADESI (KELUARGA BERDUKA DESA SIAGA) DI KABUPATEN SLEMAN

D.I. YOGYAKARTA

Hendy Setiawan ${ }^{1}$, Fariza Ikhsanditya ${ }^{2}$

1,2 Departemen IImu Pemerintahan, Universitas Muhammadiyah Yogyakarta, Yogyakarta,

Indonesia

PROVINSI “ISTIMEWA MELAYU KEPULAUAN RIAU” (GAGASAN PERMULAAN)

Muchid Albintani', Auradian Marta ${ }^{2}$

1,2 Jurusan IImu Pemerintahan, Fakultas IImu Sosial dan IImu Politik, Universitas Riau

KADERISASI DAN PENETAPAN CALON LEGISLATIF PADA PARTAI POLITIK (Studi DPD

Partai Nasional Demokrat Seram Bagian Barat 2019

Fandi Ahmad Sintani ${ }^{1}$, Wahab Tuanaya ${ }^{2}$, Marno Wance ${ }^{3}$

1,2,3 Jurusan IImu Pemerintahan, Universitas Pattimura, Indonesia

$75-90$

FACTORS THAT AFFECT DELIBERATION OF MAGUWOHARJO VILLAGE DEVELOPMENT

PLANNING SUB-DISTRICT DEPOK REGENCY SLEMAN YOGYAKARTA

Muhammad Rafi ${ }^{1}$, Ulung Pribadi2, Fajar Rahmanto ${ }^{3}$

1,2,3 Department of Government Affairs and Administration, Universitas Muhammadiyah

Yogyakarta, Indonesia

SURVEY KEPUASAN MASYARAKAT (SKM) PADA BADAN PENDAPATAN DAERAH

KABUPATEN BINTAN

Suherry ${ }^{1}$, Billy Jenawi², Rendra Setyadihardja ${ }^{3}$, Zamzami A. Karim4,

Firman Setiawan ${ }^{5}$, Rany Angraini ${ }^{6}$

$102-112$

1,2,3,4 STISIPOL Raja Haji, Tanjungpinang, Indonesia

5,6 Bapelitbang, Bintan, Indonesia

PERAN DEWAN PERWAKILAN DAERAH (DPD) DALAM PEMBENTUKAN DAERAH

OTONOMI BARU (DOB) DI WILAYAH PROVINSI MALUKU UTARA

Abdulhalil Hi. Ibrahim ${ }^{1}$, Bakri La Suhu2, Rifjal Tifandy 3 Marno Wance 4

1,2,3 IImu Pemerintahan Universitas Muhammadiyah Maluku Utara, Kota Ternate, Indonesia

$113-127$

${ }^{4}$ IImu Pemerintahan, Universitas Pattimura, Kota Ambon, Indonesia 


\title{
INNOVATION HUB: MEDIA KOLABORASI MENUJU PEMERINTAHAN DAERAH INOVATIF
}

\author{
Herie Saksono \\ Badan Penelitian dan Pengembangan (BPP) Kementerian Dalam Negeri, Jakarta, Indonesia \\ E-mail: herie.saksono26@gmail.com
}

\begin{abstract}
ABSTRAK
Abstrak: Era digital menuntut pemerintahan daerah menjadi lebih inovatif dalam penyelenggaraan tata kelola pemerintahannya. Inovasi menjadi keniscayaan dalam perumusan kebijakan agar lebih berkualitas dan implementatif, penyediaan layanan menjadi lebih prima, ultima, dan optima, mempercepat kesejahteraan masyarakat, meningkatkan investasi, dan menciptakan kemandirian daerah agar memiliki keunggulan dan daya saing. Persoalannya, berdasarkan fakta empiris masih terdapat banyak pemerintahan daerah (pemda) yang belum dapat dikategorikan sebagai pemda inovatif. Apa strategi yang tepat untuk mengubahnya, sehingga pemda lebih inovatif? Penelitian ini merupakan pengamatan selama pendampingan kegiatan inovasi daerah. Tujuannya adalah untuk menemukan solusi sekaligus mendorong terjadinya perubahan secara masif. Pendekatan yang digunakan adalah kualitatif dengan metode deskriptif-komparatif. Pengumpulan data dilakukan secara triangulasi, sedangkan analisis data bersifat induktif. Innovation hub atau dikenal dengan sebutan i-hub merupakan solusi yang berfungsi sebagai media kolaborasi antaraktor inovasi, Pemerintah, pemerintahan daerah, maupun pemerintahan desa, masyarakat, dan para pemangku kepentingan pembangunan di daerah. Melalui i-hub diharapkan terselenggara spektrum inovasi yang mencakup inovasi kepemimpinan, inovasi administrasi, inovasi manajemen, inovasi kebijakan, inovasi sosial, dan inovasi teknologi serta disrupsi inovasi. Secara umum dapat ditegaskan bahwa i-hub merupakan media kolaboratif yang mampu membentuk ekosistem inovasi, mengakselerasi inovasi, mencipta inovator, dan membangun pemerintahan daerah yang dinamis dan berkelanjutan. Pada saatnya, i-hub menjadi pemicu inovasi dan peubah pemerintahan daerah menjadi lebih dinamis, kreatif, adaptif, inovatif, produktif, futuristik, dan prospektif. Direkomendasikan kepada setiap pemda agar segera berubah, mendorong mewujudnya pelembagaan i-hub, dan mengelolanya secara kolaboratif untuk menumbuhkan inovasi daerah.
\end{abstract}

\section{Kata Kunci: Innovation Hub, Pemerintahan Kolaboratif, dan Pemerintahan Daerah Inovatif}

\begin{abstract}
The digital age is demanding local governments to become more innovative in their governance. Innovation is a necessity in the formulation of policies to be more qualified and implementative, service provision becomes more excellent, ultimate and optimal, accelerating public welfare, increasing investment, and creating regional independence in order to have excellence and competitiveness. The problem is, based on empirical facts there are still many local governments (LGs) that cannot be categorized as innovative LGs. What is the right strategy to change it so that local governments are more innovative? This study is an observation during the facilitation of regional innovation activities. The goal is to find solutions while simultaneously driving massive change. The method used is qualitative with descriptive-comparative analysis. Data collection is done by triangulation, while data analysis is inductive. Innovation hub (i-hub) is a solution that functions as a medium of collaboration between innovation actors, the Government, regional governments, as well as village governments, communities, and development stakeholders in the regions. Through the innovation hub, it is expected that an innovation spectrum will be held that includes leadership innovation, administrative innovation, management innovation, policy innovation, social innovation,
\end{abstract}


technological innovation, and innovation disruption. In general, it can be emphasized that the innovation hub is a collaborative media that is able to shape the innovation ecosystem, accelerate innovation, create innovators, and build dynamic and sustainable local government. In due time, the innovation hub triggers innovation and changes in local government to become more dynamic, creative, adaptive, innovative, productive, futuristic, and prospective. It is recommended that each local government change immediately, encourage the institutionalization of $i$-hub, and manage it collaboratively to foster regional innovation.

\section{Keywords: Innovation Hub, Collaborative Governance, and Innovative Local Government}

\section{PENDAHULUAN}

Medio September 2017 merupakan momen penting karena untuk pertama kalinya Indonesia memiliki regulasi yang secara spesifik mengatur tentang inovasi daerah. Hal ihwal inovasi daerah tersebut diatur dalam Peraturan Pemerintah (PP) Nomor 38 Tahun 2017 tentang Inovasi Daerah yang diundangkan pada 15 September 2017 (Indonesia, 2017). Sesungguhnya, cikal bakal inovasi daerah telah diinisiasi Badan Penelitian dan Pengembangan (BPP) Kementerian Dalam Negeri bersama-sama dengan Kementerian Negara Riset dan Teknologi pada 2011. Selanjutnya, secara bersama memformulasikan pengaturan inovasi dan menetapkannya menjadi Peraturan Bersama (Perber) Menteri Negara Riset dan Teknologi dan Menteri Dalam Negeri Nomor 03 Tahun 2012 dan Nomor 36 Tahun 2012 tentang Penguatan Sistem Inovasi Daerah atau yang lebih popular dikenal dengan istilah "SIDa". Terlepas dari berbagai polemik tentang keberhasilan SIDa, namun patut diakui bahwa semenjak itulah, pemerintahan daerah semakin menyadari pentingnya inovasi untuk mengakselerasi pencapaian tujuan otonomi daerah.

Perubahan tatanan global turut memengaruhi dinamika pemerintahan dalam negeri. Seiring dengan itu, era digitalisasi pun menghendaki inovasi demi perubahan fundamental. Begitu pula halnya dengan pencapaian tujuan otonomi daerah, realisasinya semakin cepat dan berkualitas ketika memasukkan inovasi dalam penyelenggaraan pemerintahan daerah. Hal ini selaras dengan pernyataan konsideran menimbang huruf $\mathrm{b}$ UndangUndang (UU) Nomor 23 Tahun 2014 tentang Pemerintahan Daerah bahwa penyelenggaraan pemerintahan daerah diarahkan untuk mempercepat terwujudnya kesejahteraan masyarakat melalui peningkatan pelayanan, pemberdayaan, dan peran serta masyarakat, serta peningkatan daya saing daerah dengan memperhatikan prinsip demokrasi, pemerataan, keadilan, dan kekhasan suatu daerah dalam sistem Negara Kesatuan Republik Indonesia (NKRI).

Pemerintah daerah (pemda) menjadi pencipta kondisi ideal dan iklim kondusif bagi tercapainya tujuan otonomi daerah. Namun, keadaan ini belum sempurna manakala motor penggeraknya, yakni aparatur sipil negara (ASN) ternyata belum mengenal, memahami, menguasai, dan bahkan mampu berinovasi. Mengetahui kondisi tersebut, dibangunlah kesadaran dan pemahaman pemda, ASN, dan masyarakat agar memiliki kuriositas dan semangat berinovasi. Target yang hendak dicapai ialah pemda inovatif, ASN kreatif, dan 
masyarakat yang produktif. Sebab, inovasi merupakan segala bentuk perubahan yang menjadi solusi dan acuan bagi peningkatan kinerja penyelenggaraan pemerintahan dalam negeri.

Era digitalisasi telah merubah secara signifikan tata kelola pemerintahan di seluruh dunia. Inovasi menjadi keniscayaan, terutama dalam perumusan kebijakan dan pelayanan publik. Masyarakat membutuhkan kebijakan yang lebih berkualitas, implementatif, dan berbasis bukti. Masyarakat semakin cerdas dan meminta layanan yang lebih unggul (prima, ultima, dan optima). Hasil Indeks Inovasi Daerah (IID) Tahun 2018 yang dirilis oleh BPP KDN semakin mengukuhkan kondisi empiris, bahwa senyatanya masih lebih banyak pemda yang menyandang status "Tidak Inovatif" (Lampiran Surat Kepala BPP Kementerian Dalam Negeri kepada Bupati/Walikota, Nomor 002.6/3444/Litbang, tertanggal 22 Agustus 2019, Hal: Hasil Indeks Inovasi Daerah Tahun 2018). Keadaan ini dapat dimaknai bahwa sebagian besar pemda masih berorientasi business as usual ketika melaksanakan tata kelola pemerintahan daerahnya.

$$
\text { Perkembangan inovasi, }
$$
komersialisasi, manfaat, beserta implikasinya perlu diukur, dievaluasi, dan dinilai secara komprehensif. Sebab, setiap pemda harus mengetahui posisi (positioning), keberadaan (existence), dan status kinerja (performance) dalam berinovasi. Pertanyaannya, bagaimana posisi masing-masing pemda dalam berinovasi? Strategi apa yang diperlukan untuk mengubah pemda menjadi lebih inovatif? Studi ini merupakan observasi selama mendampingi pemda dalam menginisiasi, mengelola, memperkuat SIDa, dan menciptakan inovasi daerah. Pengamatan dimaksudkan untuk mengetahui kesamaan maupun perbedaan pemda dalam merespon kebutuhan inovasi. Selain itu, menawarkan solusi agar pemda dapat menciptakan ekosistem inovasi sebagaimana diamanatkan dalam SIDa. Sebab, upaya menciptakan inovasi telah menjadi kebutuhan dasar dan urgen bagi peningkatan kinerja penyelenggaraan pemerintahan daerah. Selain itu, untuk mendorong pelembagaan innovation hub (i-hub) sebagai salah satu upaya meningkatkan kualitas, kuantitas, manfaat, kebermaknaan, dan dampak inovasi daerah.

\section{KERANGKA TEORI}

Salah satu problematika inovasi adalah pengertian/definisi inovasi itu sendiri. Hingga saat ini banyak ditemuikan definisi disertai deskripsi yang dibuat/dijelaskan oleh para pakar, peneliti, perumus kebijakan, dan birokrasi pemerintahan serta para inovator sebagai pelaku utama dan/atau aktor inovasi. Secara kontradiktif, kemanfaatan inovasi justru telah dirasakan seluruh pihak yang berkepentingan dengan inovasi maupun para pengguna inovasi (users). Inovasi menjadi penting dan memiliki peran krusial dalam pertumbuhan, kelangsungan hidup, dan keberhasilan organisasi (Tohidi \& Jabbari, 2011, p. 538). Selain itu, dinyatakan pula bahwa masalah utama dalam manajemen inovasi adalah tidak adanya definisi tunggal antara peneliti (researchers), pembuat kebijakan 
(policymakers), dan pihak berwenang (authorities).

Dalam perspektif proses, inovasi melalui 3 (tiga) langkah utama, yakni: i) ide (atau penemuan) "sesuatu yang baru" [produk, layanan atau proses (organisasi atau teknologi)]; ii) pengembangan (produksi, "melakukan") dari "sesuatu yang baru"; dan iii) komersialisasi (difusi, "penjualan") dari "sesuatu yang baru" (Kotsemir \& Meissner, 2013, p. 5). Sementara itu, OECD atau Organisasi Kerja Sama dan Pembangunan Ekonomi (Organisation for Economic Co-operation and Development) memberi pengertian inovasi di sektor publik: Innovation in the public sector refers to significant improvements to public administration and/or services. Drawing on definitions adopted for the business sector (Oslo Manual) and their adaptation in the Measuring Public Innovation (MEPIN) project, public-sector innovation can be defined as the implementation by a publicsector organisation of new or significantly improved operations or products (OECD, 2012, p. 181).

Mengacu pada ketentuan Pasal 1 angka 1 PP Nomor 38 Tahun 2017 tentang Inovasi Daerah, terminologi inovasi daerah dimaknai sebagai semua bentuk pembaharuan dalam penyelenggaraan pemerintahan daerah. Penyelenggaraan pemerintahan daerah adalah penyelenggaraan Urusan Pemerintahan oleh Pemerintah Daerah dan Dewan Perwakilan Rakyat Daerah (DPRD) menurut asas otonomi dan tugas pembantuan dengan prinsip otonomi seluas-luasnya dalam sistem dan prinsip NKRI sebagaimana dimaksud dalam
Undang-Undang Dasar Negara Republik Indonesia Tahun 1945.

Studi ini memfokuskan bahasannya kepada inovasi daerah dan dinamikanya melalui pelembagaan innovation hub. Dalam konteks ini, inovasi adalah pengimplementasian hal ihwal baru yang bermanfaat untuk meningkatkan kualitas pelayanan publik dan tata kelola pemerintahan beserta perluasan kemanfaatan lainnya (public beneficiaries). Pada fase inilah ditanamkan (embeded) inovasi ke dalam tubuh birokrasi pemerintahan daerah. Jadi inovasi dan pemerintahan daerah menjadi satu kesatuan yang melebur bagaikan sekeping mata uang dengan kedua sisinya. Sisi pemerintahan daerah mencakup kepala daerah, anggota DPRD, perangkat daerah, ASN, dan masyarakatnya yang menjadi motor perubahan melalui inovasi daerah. Sisi lainnya adalah Sistem Inovasi Daerah (SIDa) itu sendiri sebagai sistem penghasil inovasi daerah. Pertimbangannya, SIDa adalah keseluruhan proses dalam satu sistem untuk menumbuhkembangkan inovasi yang diinisiasi/dilakukan antarinstitusi Pemerintah (Pusat), pemerintahan daerah (pemda), lembaga kelitbangan, lembaga pendidikan, lembaga penunjang inovasi, dunia usaha, dan masyarakat di daerah.

$$
\text { Lantas, adakah pengertian }
$$

"Pemerintahan Daerah Inovatif"?

Pemerintahan Daerah Inovatif adalah pemerintah daerah (pemda) dan DPRD yang mengimplementasikan cara-cara baru yang inovatif dalam penyelenggaraan tata kelola pemerintahan, pelayanan publik, dan pencapaian tujuan otonomi daerahnya, sehingga terjadi peningkatan 
kinerja dan percepatan pencapaian target masyarakat yang lebih sejahtera.
Dalam upaya
memahami

kolaborasi, ARACY atau Australian Research Alliance for Children and Youth (Youth, 2013, pp. 1-3) mendeskripsikan bahwa kolaborsi umumnya merujuk pada individu atau organisasi yang bekerja bersama untuk mengatasi masalah dan memberikan hasil yang efektif. Keadaan ini menegaskan bahwa kolaborasi diperlukan untuk mewujudkan produk yang tidak mungkin dicapai bila dikerjakan sendiri. Melalui kolaborasi tercipta sinergi yang diwujudkan dengan menggabungkan upaya dan keahlian, sehingga dapat menghasilkan manfaat lebih besar daripada yang dicapai melalui upaya individu. Manfaat unggul yang diciptakan melalui upaya gabungan ini dikenal sebagai keunggulan kolaboratif. Kolaborasi ditandai oleh hubungan yang kuat dan sangat saling bergantung. Dalam kondisi ini disadari bahwa untuk mencapai hasil, diperlukan perubahan cara berpikir, berperilaku, dan beroperasi. Mengacu pada definisi tersebut, maka pengertian kolaborasi dalam studi ini adalah kerja bersama para pemangku kepentingan dalam innovation hub untuk menghasilkan keunggulan kolaboratif, yakni: inovasi daerah.

Istilah innovation $h u b$ atau $i-h u b$ belum begitu akrab dan sering terdengar di kalangan masyarakat. Penyebutannya menjadi semakin jarang karena secara praktis memang nyaris tidak ditemukan apa yang dimaksud dengan $i$ - $h u b$ tersebut. Kata " $h u b$ " pun sulit dicarikan terjemahan atau padanan kata yang sesuai dalam Bahasa Indonesia. Akibatnya, istilah innovation hub semakin asing bagi masyarakat Indonesia. Dalam Webster's New World (Neufeldt \& Guralnik., 1991, p. 656) $h u b$ didefinisikan dengan: hub (hub) $n$. [[prob. Ult. < IE base *keu-, to bend mound, base]] 1: the center part of a wheel, etc.; the part fastened to the axle, or turning on it $\mathbf{2}$ a center of interest, importance, or activity. Jadi, kata hub lebih berfungsi menyatukan kendali (center), menggerakkan, memercepat, dan sebagai pusat perhatian, kepentingan, dan aktivitas lainnya.

Innovation hub (i-hub) seringkali diterjemahkan simpul inovasi (Saksono, 2018 , p. 113). Innovation hub didefinisikan sebagai sarana berinteraksi yang mengintegrasikan segenap aktor inovasi baik secara fisik (offline) atau virtual online atau perpaduan kedua aktivitas (online \& offline) untuk saling berbagi, belajar, berkolaborasi, dan mengeksplorasi ilmu pengetahuan dan teknologi demi terciptanya inovasi agar mampu bersaing secara global

Keberadaan innovation hub diharapkan mampu menyulut inovasi, terutama inovasi di sektor publik. Bank Dunia dalam laporan berjudul Igniting Innovation: Rethinking the Role of Government in Emerging Europe and Central Asia dan telah dirilis di Moscow pada 10 Oktober 2011 (Bank, 2011), mengharapkan agar pemerintah di kawasan Eropa dan Asia Tengah menghindari jebakan dan menerapkan kebijakan yang secara efektif akan membuat inovasi dan adopsi teknologi menjadi bagian sentral dari strategi pembangunan dan pertumbuhan nasional.

Berkenaan dengan hal ini, inovasi dan kreativitas memiliki kesetaraan dalam tujuan (output). Jika inovasi bermuara pada 
komersialisasi produk agar menghasilkan nilai tambah ekonomi, maka kreativitas pun dapat menghasilkan produk barang/jasa yang terintegrasi ke dalam ekonomi kreatif. Ekonomi kreatif memerlukan inovasi dalam mentransformasikan ide kreatif menjadi sesuatu yang berharga, demikian pula inovasi akan penggerak kreativitas (Sidauruk \& Saksono, 2018, p. 88).

\section{METODE PENELITIAN}

Studi ini menggunakan pendekatan kualitatif dengan metode deskriptifkomparatif. Unit analisis dalam studi ini adalah perangkat daerah yang menyelenggarakan fungsi penunjang urusan pemerintahan daerah bidang penelitian dan pengembangan (kelitbangan). Dalam konteks ini, fungsi penunjang kelitbangan di Kota Kotamobagu penyelenggaraannya diampu oleh Badan Perencanaan, Penelitian, dan Pengembangan Daerah (BP3D), sedangkan di Kota Baubau diampu oleh Badan Penelitian dan Pengembangan Daerah (BPPD).

Kebutuhan data primer dan data sekunder diperoleh ketika melakukan pendampingan kegiatan kelitbangan baik di BP3D Kota Kotamobagu maupun BPPD Kota Baubau dalam kurun waktu 2017 dan 2018. Pengumpulan beberapa data/informasi lainnya dilakukan secara triangulasi dan diperoleh melalui Badan Pusat Statistik (BPS) Kota Kotamobagu, BPS Kota Baubau, BPS Provinsi Sulawesi Utara, BPS Provinsi Sulawesi Tenggara, dan BPS Pusat. Teknik pengumpulan data yang digunakan adalah observasi, wawancara, dan studi pustaka. Sementara itu, untuk analisis data dilakukan melalui
3 (tiga) alur kegiatan sebagaimana Miles dan (Miles \& Huberman, 1994, p. 12), yakni: i) reduksi data; ii) penyajian data; dan iii) penarikan kesimpulan/verifikasi.

\section{HASIL DAN PEMBAHASAN}

\section{Innovation Hub Sebagai Penggerak Inovasi Daerah}

Berdasarkan hasil observasi ditemukan bahwa setiap pemda memiliki agenda strategis dan spesifik untuk mengaktualisasikan inovasi daerah. Pertimbangannya adalah kesesuaian dengan target capaian visi-misi, gaya kepemimpinan daerah, karakteristik kewilayahan, kearifan lokal, urgensi pelayanan, dan kepentingan lainnya. Artinya, setiap pemda pasti berupaya menyulut inovasi untuk mengakselerasi pembangunan, mereduksi kemiskinan, menaikkan pendapatan, memerbaiki tingkat kesejahteraan warga, dan meningkatkan daya saing daerahnya.

Dalam penyelenggaraan aktivitas inovasinya, baik BP3D Kota Kotamobagu maupun BPPD Kota Baubau telah melakukan pelembagaan innovation hub. Sebab, manajemen inovasi memerlukan kerja kolaboratif antarpemangku kepentingan inovasi di daerah. Innovation hub menjadi wadah yang mampu mengidentifikasi permasalahan, mengakomodasi ide/gagasan, menjalin kebersamaan, membangun jejaring, merumuskan kebijakan, dan menyulut inovasi sebagai solusi untuk mereduksi permasalahan penyelenggaraan urusan pemerintahan daerah dan meningkatkan kinerja pemda.

Secara operasional, innovation hub menjadi kanal/media komunikasi antara peneliti, inventor/inovator/kreator, 
pembuat kebijakan, pimpinan daerah, dunia usaha (industry), dan masyarakat selaku penerima manfaat (people beneficiaries). Aktivasi pekerjaannya pun dapat dilakukan secara online ataupun offline, sehingga menembus batas ruang dan waktu. Para pelaku innovation hub pun melebur dalam satu tim yang bekerja leluasa dengan komunikasi yang dibangun secara egaliter, sehingga dapat memunculkan kreativitas dan inovasi. Tidak ada lagi sekat imajiner, hirarki birokrasi, dan cara kerja birokrat yang sangat procedural dan dapat mematikan kreativitas aktor innovation hub. Pekerjaan difokuskan pada proses yang berkualitas dengan orientasi pada hasil yang memiliki nilai komersial (commercialization) dan/atau kemanfaatan publik tinggi (public beneficiaries). Hasil akhir dipublikasikan untuk mendapatkan masukan dalam rangka penyempurnaan produk, peningkatan nilai tambah, bahkan memberikan wajah baru bagi penyelenggaraan otonomi daerah (Saksono, 2016, p. 137).

$$
\text { Deskripsi atas aktualisasi }
$$
penyelenggaraan inovasi daerah yang dilakukan oleh BP3D Kota Kotamobagu dan BPPD Kota Baubau disandingkan secara komparatif pada Tabel 1.

Tabel 1.

Komparasi Aktualisasi Innovation Hub Di Kota Kotamobagu \& Kota Baubau

\begin{tabular}{|c|c|c|c|}
\hline No. & Aspek & BP3D Kota Kotamobagu & BPPD Kota Baubau \\
\hline 1. & $\begin{array}{l}\text { Karakteristik } \\
\text { Kewilayahan }\end{array}$ & $\begin{array}{l}\text { Daerah Tertutup (Landlock Region) di Pulau } \\
\text { Sulawesi }\end{array}$ & $\begin{array}{l}\text { Daerah Pesisir (Coastal Region) di } \\
\text { Pulau Buton }\end{array}$ \\
\hline 2. & Regulasi & $\begin{array}{l}\text { Belum ada Peraturan Walikota Kotamobagu tentang } \\
\text { Penguatan Roadmap Sistem Inovasi Daerah }\end{array}$ & $\begin{array}{l}\text { Belum ada Peraturan Walikota } \\
\text { Baubau tentang Penguatan Roadmap } \\
\text { Sistem Inovasi Daerah (SIDa) }\end{array}$ \\
\hline 3. & $\begin{array}{l}\text { Kelembagaan/ } \\
\text { Tata Kelola }\end{array}$ & $\begin{array}{l}\text { Bidang (Bagian dari Perangkat Daerah) } \\
\text { Bidang Penelitian dan Pengembangan pada Badan } \\
\text { Perencanaan, Penelitian, dan Pengembangan Daerah } \\
\text { (BP3D) Kota Kotamobagu }\end{array}$ & $\begin{array}{l}\text { Badan (Perangkat Daerah) } \\
\text { Badan Penelitian dan Pengembangan } \\
\text { Daerah (BPPD) Kota Baubau }\end{array}$ \\
\hline 4. & SDM Pengelola & $\begin{array}{l}\text { Pejabat Administrator } \\
\text { (Bidang - Setara Es. III) } \\
\text { Jumlah ASN = } 5 \text { (lima) }\end{array}$ & $\begin{array}{l}\text { Pejabat Pimpinan Tinggi Pertama } \\
\text { (Badan - Setara Es. II) } \\
\text { Jumlah ASN }=20 \text { (dua puluh) }\end{array}$ \\
\hline 5. & $\begin{array}{l}\text { Kolaborasi } \\
\text { Aktor }\end{array}$ & $\begin{array}{l}\text { 1) Akademisi; } \\
\text { 2) Walikota/Wakil Walikota Kotamobagu; } \\
\text { 3) Perangkat Daerah Kota Kotamobagu; } \\
\text { 4) Bank Indonesia Perwakilan Provinsi Sulawesi } \\
\text { Utara; } \\
\text { 5) RKB Kota Kotamobagu [PT. Bank Rakyat } \\
\text { Indonesia (Persero) Tbk.]; } \\
\text { 6) Sangadi (Kades) Desa Bilalang I; } \\
\text { 7) Kelompok Petani Kopi; } \\
\text { 8) UMKM/Pedagang Kopi; dan } \\
\text { 9) Pengusaha Resto \& Kafe. }\end{array}$ & $\begin{array}{ll}\text { 1) } & \text { Akademisi; } \\
\text { 2) Walikota/Wakil Walikota } \\
\text { Baubau; } \\
\text { 3) Perangkat Daerah Kota Baubau; } \\
\text { 4) RKB Kota Baubau [PT. Telkom } \\
\text { Indonesia (Persero) Tbk]; } \\
\text { 5) Komunitas Kreatif - Baubau } \\
\text { Creative Forum (BBCF); } \\
\text { 6) Wirausahawan; } \\
\text { 7) UMKM; } \\
\text { 8) Jurnalis/Media; dan } \\
\text { 9) Pengusaha Resto \& Kafe. }\end{array}$ \\
\hline 6. & Penganggaran & Tersebar pada beberapa perangkat daerah & $\begin{array}{l}\text { Tersebar pada beberapa perangkat } \\
\text { daerah }\end{array}$ \\
\hline
\end{tabular}


(1) NAKHODA:

JURNAL

ILMU PEMERINTAHAN
NAKHODA: JURNAL ILMU PEMERINTAHAN

Edisi Januari-Juni Tahun 2020 Volume: 19 Nomor: 1

ISSN : 1829-5827 | E-ISSN : 2656-5277

DOI : https://doi.org/10.35967/jipn

https://nakhoda.ejournal.unri.ac.id/index.php/JIPN

\begin{tabular}{|c|c|c|c|}
\hline No. & Aspek & BP3D Kota Kotamobagu & BPPD Kota Baubau \\
\hline 7. & MoU Kerjasama & Tidak ada & $\begin{array}{l}\text { 1) Universitas Hasanuddin; } \\
\text { 2) Institut Pemerintahan Dalam } \\
\text { Negeri (IPDN); } \\
\text { 3) Universitas Halu Oleo; } \\
\text { 4) Universitas Muhammadiyah } \\
\text { Buton; } \\
\text { 5) Universitas Dayanu Ikhsanuddin }\end{array}$ \\
\hline 8. & Target (Output) & Kopi menjadi Produk Unggulan Daerah (PUD) & $\begin{array}{l}\text { Mewujudkan Baubau Kota Kreatif/ } \\
\text { Jaringan Kota Kreatif Indonesia }\end{array}$ \\
\hline 9. & $\begin{array}{l}\text { Produk } \\
\text { Unggulan }\end{array}$ & $\begin{array}{l}\text { Lokasi Kawasan Pertanian Nasional: } \\
\text { a. Komoditas Prioritas Tanaman Pangan Padi; } \\
\text { b. Komoditas Prioritas Perkebunan Kopi }\end{array}$ & $\begin{array}{l}\text { Lokasi Kawasan Pertanian Nasional: } \\
\text { a. Komoditas Prioritas Tanaman } \\
\text { Pangan Jagung. }\end{array}$ \\
\hline 10. & Kendala & $\begin{array}{l}\text { Pengembangan pangsa pasar produk kopi dan } \\
\text { inovasi produk kopi }\end{array}$ & $\begin{array}{l}\text { Penyiapan administratif, teknis- } \\
\text { operasional, dan manajerial Kota } \\
\text { Kreatif }\end{array}$ \\
\hline
\end{tabular}

Sumber: Hasil Observasi. Data Diolah. 2019.

Keterangan: ${ }^{*}$ SP3F adalah sarana-prasarana, peralatan, perlengkapan, dan fasilitas pendukung lainnya.

Tabel 1 menampilkan kondisi faktual yang direfleksikan melalui 10 (sepuluh) aspek terintegrasi yang dianggap layak merepresentasikan pelembagaan innovation hub. Secara operasional, kesepuluh aspek tersebut mengindikasikan tata cara dan tata kelola innovation hub melalui aktivitas kelitbangan yang dilakukan oleh BP3D Kota Kotamobagu dan BPPD Kota Baubau. Aktivitas kelitbangan sebagaimana dinyatakan dalam ketentuan Pasal 4 Peraturan Menteri Dalam Negeri Nomor 17 Tahun 2016 tentang Pedoman Penelitian dan Pengembangan di Kementerian Dalam Negeri dan Pemerintahan Daerah adalah penelitian, pengembangan, pengkajian, penerapan, perekayasaan, pengoperasian, dan evaluasi kebijakan.

Secara spesifik akan dibahas beberapa aspek yang memiliki perbedaan signifikan dari kedua kota tersebut. Pertama, bertolak dari karakteristik kewilayahannya, terdapat perbedaan signifikan antara Kota Kotamobagu dengan Kota Baubau. Jika Kota Kotamobagu berada di ketinggian sebagai wilayah terkunci (landlock region) karena tidak memiliki wilayah laut dan tidak ada akses langsung ke laut, maka berbeda halnya dengan Kota Baubau yang berada di Pulau Buton dan merupakan kota yang terletak di tepi laut (coastal). Tentunya diperlukan upaya ekstra dan tindakan cerdas dari seluruh penanggung jawab aktivitas kelitbangan untuk membantu kelancaran aksesibilitas dan konektivitas serta mobilitas berbagai komoditas dari Kota Kotamobagu ke berbagai daerah lain dan sebaliknya.

Kedua, dalam perspektif administratif kerjasama kelitbangan (joint research), nampak bahwa BP3D Kota Kotamobagu belum melakukan kerjasama kelitbangan dengan perguruan tinggi. Pelaksanaan aktivitas kelitbangannya dilakukan berdasarkan proses pengadaan barang/jasa berupa jasa konsultansi. Berbeda dengan BPPD Kota Baubau yang telah memiliki MoU Kerjasama Kelitbangan dengan perguruan tinggi dan mengikutsertakan para pemangku kepentingan lainnya untuk membantu menuntaskan agenda kelitbangan, 
menciptakan inovasi, dan meningkatkan produktivitasnya.

Ketiga, dalam perspektif target yang hendak dicapai, BP3D Kota Kotamobagu sangat aktif memfasilitasi dan mendukung promosi Kopi Kotamobagu sebagai produk unggulan daerah (PUD). Kondisinya berbeda di BPPD Kota Baubau, dimana masih melakukan penyiapan konsep dan melakukan penatakelolaan administrasi dan dokumentasi Kota Kreatif. Dokumentasi tersebut diperlukan untuk merealisasikan Kota Baubau sebagai Kota Kreatif yang terhimpun dalam Jaringan Kota Kreatif Indonesia atau Indonesia Creative City Network (ICCN).

Secara umum, BP3D Kota Kotamobagu dan BPPD Kota Baubau telah berkolaborasi dengan Pemerintah (Pusat). Penetapan produk unggulan (Aspek Kesembilan) mengacu pada Lampiran Keputusan Menteri Pertanian Nomor 472/Kpts/RC.040/6/2018 tentang Lokasi Kawasan Pertanian Nasional, dimana Kota Kotamobagu ditetapkan sebagai Lokasi Kawasan Pertanian Nasional Komoditas Prioritas Tanaman Pangan berupa Padi. Selain itu, Kota Kotamobagu ditetapkan pula sebagai lokasi Kawasan pertanian nasional komoditas prioritas perkebunan kopi. Kawasan pertanian nasional di Kota Kotamobagu dikembangkan untuk komoditas prioritas sub sektor tanaman pangan, hortikultura, perkebunan, dan peternakan sesuai dengan arah dan kebijakan Kementerian Pertanian sebagaimana Keputusan Menteri Pertanian Nomor 472/Kpts/RC.040/6/2018 tentang Lokasi Kawasan Pertanian Nasional. Dalam upaya mendukung kelembagaan ekonomi petani, telah dilakukan tindak lanjut atas Peraturan Menteri Pertanian Nomor 18/Permentan/RC.040/4/2018 tentang Pedoman Pengembangan Kawasan Pertanian Berbasis Korporasi Petani. Dalam konteks ini, perlu dibangun korporasi petani padi dan petani kopi di Kota Kotamobagu. Hal ini sejalan dengan ketentuan Pasal 1 Angka 2 yang menyatakan bahwa Korporasi Petani adalah kelembagaan ekonomi petani berbadan hukum berbentuk koperasi atau badan hukum lain dengan sebagian besar kepemilikan modal dimiliki oleh petani.

Begitu pula halnya dengan penyelenggaraan industrialisasi di daerah. Mengacu pada ketentuan Pasal 2 Peraturan Menteri Perindustrian Nomor 83/MIND/PER/12/2013 tentang Peta Panduan Pengembangan Kompetensi Inti Industri Kota Kotamobagu, dinyatakan bahwa industri pengolahan kelapa dengan fokus pada kemampuan mengolah kelapa menjadi minyak kelapa, merupakan Kompetensi Inti Industri (KII) Kota Kotamobagu. Hal ini mengandung makna bahwa potensi unggulan daerah Kota Kotamobagu berupa kelapa patut mendapatkan porsi pengolahan melalui industry yang dikelola dan berada di Kota Kotamobagu.

Sementara untuk Kota Baubau hanya ditetapkan sebagai Lokasi Kawasan Pertanian Nasional Komoditas Prioritas Tanaman Pangan berupa Jagung. Di sisi lain, belum terdapat pengaturan tentang Peta Panduan Pengembangan Kompetensi Inti Industri Kota Baubau. Padahal Peta Panduan Pengembangan Kompetensi Inti Industri diperlukan untuk pengolahan produk unggulan daerah Kota Baubau. Kondisi ini menuntut keberadaan innovation hub yang difasilitasi oleh 
institusi penanggung jawab aktivitas kelitbangan. Innovation hub berfungsi sebagai katalisator, dimana para aktor inovasi berinteraksi dan berkontribusi menciptakan inovasi yang mengakselerasi pembangunan daerah dan meningkatkan kesejahteraan.
Keberadaan innovation hub menjadi magnet yang mampu memotivasi 12 (duabelas) aktor/pemangku kepentingan inovasi di daerah untuk menghasilkan keunggulan kolaboratif diilustrasikan dalam Gambar 1 berikut.

\section{Gambar 1. Innovation Hub Sebagai Wadah Kolaborasi Penghasil Inovasi Daerah}

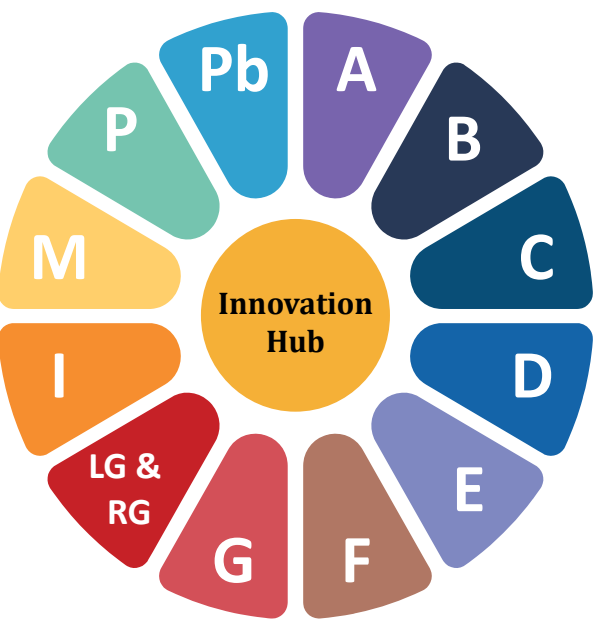

Innovation Hub \& Pemangku Kepentingan

Innovation hub menjadi solusi. Fungsinya sebagai media kolaborasi 12 (duabelas) pemangku kepentingan inovasi daerah antara lain: Pemerintah, pemerintahan daerah dan pemerintahan desa, masyarakat, dan pemangku kepentingan lainnya di daerah. Melalui $i$ hub diharapkan terselenggara spektrum inovasi yang mencakup inovasi kepemimpinan, inovasi administrasi, inovasi manajemen, inovasi kebijakan, inovasi sosial, dan inovasi teknologi serta disrupsi inovasi. Secara umum dapat ditegaskan bahwa $i$-hub merupakan media kolaboratif yang mampu membentuk ekosistem inovasi, mengakselerasi inovasi, mencipta inovator, dan membangun pemerintahan daerah yang dinamis dan berkelanjutan.

\section{Dinamika Inovasi Daerah}

Peningkatan kinerja pemerintahan daerah menuntut adanya pembaharuan atau inovasi untuk mengakselerasi pelaksanaan urusan pemerintahan daerah, baik urusan pemerintahan wajib (pelayanan dasar dan non pelayanan dasar) maupun urusan pemerintahan pilihan. Seiring dengan itu, semenjak 2017 terjadi dinamika dalam pengelolaan inovasi daerah.

Mengacu pada proses pemasukan data Indeks Inovasi Daerah (IID), terdapat 
286 pemda yang telah melakukan pemutakhiran data (data input) inovasi daerahnya. Artinya, sekira 52,77 persen atau lebih dari separuh pemda di seluruh Indonesia memiliki keinginan untuk berubah dan melakukan inovasi. Inovasi daerah memberi implikasi terhadap dinamika berkelanjutan (sustainable dynamics) bagi penyelenggaraan pemerintahan daerah. Sebab, hanya dalam kurun waktu 1 (satu) tahun telah terjadi perubahan signifikan. Hal ini pun mengindikasikan lonjakan animo pemda dalam berinovasi sebagai terobosan untuk perbaikan kinerjanya.

Dinamika inovasi daerah mendorong keberhasilan pemda menyelenggarakan tata kelola pemerintahan, pelayanan publik, pemberdayaan masyarakat, dan peningkatan daya saing daerah. Pengukuran tingkat kedinamisan inovasi daerah dibagi ke dalam 3 (tiga) kategori, yakni: i) Sangat Inovatif; ii) Inovatif; dan iii) Kurang Inovatif. Selain itu, mengacu pada basis data wilayah administrasi pemerintahan daerah (542 daerah otonom), ditemukan beberapa pemda yang belum mengisi data (BMD) dan pemda yang sama sekali tidak memiliki data dukung inovasi daerah (TAD). Dinamika berkelanjutan penyelenggaraan inovasi daerah selama tahun 2018 disajikan pada Tabel 2 berikut.

Tabel 2.

Dinamika Inovasi Daerah Menurut Pemda Tahun 2018

\begin{tabular}{|c|c|c|c|c|c|c|c|c|c|c|c|}
\hline \multirow{2}{*}{ Pemda } & \multicolumn{10}{|c|}{ Kategori Inovasi Pemda } & \multirow{2}{*}{$\begin{array}{l}\text { Jumlah } \\
\text { Pemda }\end{array}$} \\
\hline & SI & $\%$ & I & $\%$ & $\mathbf{K I}$ & $\%$ & BMD & $\%$ & TAD & $\%$ & \\
\hline Provinsi & 10 & 29,41 & 2 & 5,88 & 11 & 32,35 & 7 & 20,59 & 4 & 11,76 & 34 \\
\hline Kabupaten & 43 & 10,36 & 14 & 3,37 & 86 & 20,72 & 61 & 14,70 & 211 & 50,84 & 415 \\
\hline Kota & 26 & 27,96 & 5 & 5,38 & 15 & 16,13 & 20 & 21,51 & 27 & 29,03 & 93 \\
\hline Jumlah & 79 & 14,58 & 21 & 3,87 & 112 & 20,66 & 88 & 16,24 & 242 & 44,65 & 542 \\
\hline
\end{tabular}

Sumber: Lampiran Surat Kepala BPP Kemendagri Nomor 002.6/3444/Litbang, tertanggal 22 Agustus 2019, Hal: Hasil Indeks Inovasi Daerah Tahun 2018. Data Diolah. 2019.

Keterangan: $\mathrm{SI}=$ Sangat Inovatif; $\mathrm{I}=$ Inovatif; $\mathrm{KI}=$ Kurang Inovatif; $\mathrm{BMD}=$ Belum Mengisi Data; $\mathrm{TAD}=$ Tidak Ada Data; $\%=$ Persentase.

Menyimak data pada Tabel 2, semakin nyata bahwa inovasi daerah masih menjadi sesuatu yang dirasakan "sulit" dan karenanya menjadi "langka". Dimungkinkan pula inovasi daerah mendapat tempat di hati penyelenggara pemerintahan daerah, sehingga belum dihayati dan dimaknai pentingnya inovasi oleh pemerintahan daerah maupun aparatur sipil negara (ASN) yang bekerja di pemerintahan daerah.

Dari 542 daerah otonom di Indonesia, terdapat 79 pemerintah daerah yang berhasil meraih status "Sangat Inovatif". Sekalipun pemda dengan status "Sangat Inovatif" dan pemda yang berstatus "Inovatif" diakumulasikan, maka jumlahnya hanya 100 daerah otonom atau hanya 18,45 persen daerah otonom yang 
telah menjadikan inovasi sebagai kebutuhan dalam upaya pemenuhan kebutuhan pelayanan publik. Dengan kata lain, 100 pemda tersebut telah mampu memahami dan berhasil memaknai pentingnya inovasi daerah, sehingga mereka terpanggil, termotivasi, dan terpacu untuk senantiasa berinovasi. Keadaan ini selaras dengan hasil studi (Saksono, 2012, p. 98), dimana kemajuan dan keberhasilan daerah otonom ditentukan oleh keberadaan kelas kreatif dan daya inovasinya. Semakin banyak kelas kreatif dan inovasi di suatu daerah, semakin mempercepat terjadinya perubahan politik, sosial, ekonomi, dan budaya yang mengarah pada kesejahteraan.

Ditemukan hal yang unik bila ditelisik dari perspektif Gubernur sebagai Wakil Pemerintah Pusat di Daerah maupun Gubernur sebagai Kepala Daerah. Data membuktikan bahwa Pemda provinsi berstatus "Kurang Inovatif" (KI) justru memiliki proporsi tertinggi, yakni: $32,35 \%$. Artinya, hingga saat ini masih terdapat 11 provinsi dari 34 provinsi yang masuk kategori "Kurang Inovatif". Padahal, eksistensi pemda provinsi merupakan Pembina dan Pengawas atas penyelenggaraan urusan pemerintahan daerah kabupaten/kota di wilayahnya.

Pembinaan dan pengawasan terhadap urusan pemerintahan yang menjadi kewenangan daerah kabupaten/kota diatur secara tegas dalam PP Nomor 33 Tahun 2018 tentang Pelaksanaan Tugas dan Wewenang Gubernur Sebagai Wakil Pemerintah Pusat. Ketentuan Pasal 1 mengatur tugas dan wewenang Gubernur Sebagai Wakil Pemerintah Pusat maupun tugas dan wewenang lainnya selain melaksanakan pembinaan dan pengawasan.
Pasal 1 ayat (1)

Dalam melaksanakan pembinaan dan pengawasan terhadap urusan pemerintahan yang menjadi kewenangan daerah kabupaten/kota dan tugas pembantuan oleh daerah kabupaten/ kota, Presiden dibantu oleh gubernur sebagai wakil Pemerintah Pusat.

Pasal 1 ayat (2)

Dalam melaksanakan pembinaan dan pengawasan sebagaimana dimaksud pada ayat (1) gubernur sebagai wakil Pemerintah Pusat mempunyai tugas:

a. mengoordinasikan pembinaan dan pengawasan penyelenggaraan tugas pembantuan di daerah kabupaten/kota;

b. melakukan monitoring, evaluasi, dan supervisi terhadap penyelenggaraan pemerintahan daerah kabupaten/kota yang ada di wilayahnya;

c. memberdayakan dan memfasilitasi daerah kabupaten/kota di wilayahnya;

d. melakukan evaluasi terhadap rancangan peraturan daerah kabupaten/kota tentang rencana pembangunan jangka panjang daerah, rencana pembangunan jangka menengah daerah, anggaran pendapatan dan belanja daerah, perubahan anggaran pendapatan dan belanja daerah, pertanggungjawaban pelaksanaan anggaran pendapatan dan belanja daerah, tata ruang daerah, pajak daerah, dan retribusi daerah;

e. melakukan pengawasan terhadap peraturan daerah kabupaten/kota; dan

f. melaksanakan tugas lain sesuai dengan ketentuan peraturan perundangundangan.

Pasal 1 ayat (3) 
Dalam melaksanakan tugas sebagaimana dimaksud ayat (2), gubernur sebagai wakil Pemerintah Pusat mempunyai wewenang:

a. membatalkan peraturan bupati/wali kota;

b. memberikan penghargaan atau sanksi kepada bupati/wali kota terkait dengan penyelenggaraan pemerintahan daerah;

c. menyelesaikan perselisihan dalam penyelenggaraan fungsi pemerintahan antardaerah kabupaten/kota dalam 1 (satu) daerah provinsi;

d. memberikan persetujuan terhadap rancangan peraturan daerah kabupaten/kota tentang pembentukan dan susunan perangkat daerah kabupaten/kota; dan

e. melaksanakan wewenang lain sesuai dengan ketentuan peraturan perundang-undangan.

Pasal 1 ayat (4)

Selain melaksanakan pembinaan dan pengawasan sebagaimana dimaksud pada ayat (1) gubernur sebagai wakil Pemerintah Pusat mempunyai tugas dan wewenang:
a. menyelaraskan perencanaan pembangunan antardaerah kabupaten/kota dan antara daerah provinsi dan daerah kabupaten/kota di wilayahnya;

b. mengoordinasikan kegiatan pemerintahan dan pembangunan antara daerah provinsi dan daerah kabupaten/kota dan antardaerah kabupaten/ kota yang ada di wilayahnya;

c. memberikan rekomendasi kepada Pemerintah Pusat atas usulan dana alokasi khusus pada daerah kabupaten/kota di wilayahnya;

d. melantik bupati/wali kota;

e. memberikan persetujuan pembentukan instansi vertikal di wilayah provinsi kecuali pembentukan instansi vertikal untuk melaksanakan urusan pemerintahan absolut dan pembentukan instansi vertikal oleh kementerian yang nomenklaturnya secara tegas disebutkan dalam Undang-Undang Dasar Negara Republik Indonesia Tahun 1945;

f. melantik kepala instansi vertikal dari kementerian dan lembaga pemerintah nonkementerian yang ditugaskan di wilayah daerah provinsi yang bersangkutan kecuali untuk kepala instansi vertikal yang melaksanakan urusan pemerintahan absolut dan kepala instansi vertikal yang dibentuk oleh kementerian yang nomenklaturnya secara tegas disebutkan dalam Undang-Undang Dasar Negara Republik Indonesia Tahun 1945; dan

g. melaksanakan tugas dan wewenang lain sesuai dengan ketentuan peraturan perundang-undangan.

Selain itu, mengacu pada ketentuan Pasal 1 ayat (4) huruf g, maka Gubernur sebagai Wakil Pemerintah Pusat memiliki peran signifikan untuk mendorong dan mengakselerasi inovasi daerah sebagaimana diamanatkan dalam UU Nomor 32 Tahun 2014 tentang Pemerintahan Daerah dan PP Nomor 38 Tahun 2017 tentang Inovasi Daerah.

Melalui observasi, diskusi terfokus, wawancara mendalam, dan penelusuran literatur, kemudian ditemukan adanya 9 (sembilan) faktor yang menjadi penyebab 
kecilnya persentase daerah inovatif. Faktor-faktor tersebut adalah:

1. kepemimpinan pemerintahan daerah (innovation leadership);

2. birokrasi yang masih sangat konvensional dan tradisional;

3. keterbatasan pemahaman, rendahnya kuriositas, kapasitas, dan kepedulian pemda;

4. kurangnya pembinaan (asistensi, sosialisasi, dan edukasi) dari Pemerintah (Pusat);

5. terbatasnya dukungan anggaran untuk berinovasi atau program/kegiatan yang inovatif;

6. ketiadaan wadah bagi para pemangku kepentingan/inventor/inovator/kreator/;

7. belum dirasakannya manfaat langsung keberadaan inovasi daerah;

8. kecilnya perhatian publik terhadap penyelenggaraan pemerintahan daerah, khususnya kepedulian akan kebutuhan inovasi guna meningkatkan kualitas layanan publik; dan

9. kekhawatiran atas keberlanjutan inovasi (innovation sustainability) yang diciptakan dan wajib diterapkan serta pengaruhnya bagi tata kelola pemerintahan daerah.

$$
\text { Inovasi daerah merupakan }
$$

instrumen pengungkit (leverage instrument) yang berimplikasi luas, cepat, dan massif, bahkan berdampak ganda (multiplier). Inovasi daerah yang berkualitas dengan jumlah memadai serta memiliki manfaat terhadap publik dapat langsung mendongkrak kinerja penyelenggaraan pemerintahan daerah.

Dinamika inovasi daerah semakin bermakna ketika setiap inovasi yang ditumbuhkan mengadopsi nilai-nilai budaya lokal sebagai suatu kearifan bersama setempat yang dimiliki dan diwarisi secara turun-temurun (Saksono, 2013, p. 4). Sebagaimana ketentuan Pasal 2 PP Nomor 38 Tahun 2017 tentang Inovasi Daerah bahwa inovasi daerah bertujuan untuk meningkatkan kinerja penyelenggaraan pemerintahan daerah. Dalam upaya mencapai tujuan tersebut, inovasi daerah diarahkan untuk memercepat terwujudnya kesejahteraan masyarakat melalui:

a. peningkatan pelayanan publik;

b. pemberdayaan dan peras serta masyarakat; dan

c. peningkatan daya saing daerah.

Mengacu kepada konten dan konteks inovasi daerah tersebut, maka hingga akhir 2018 telah berhasil dihimpun 4.075 jenis inovasi daerah yang berasal dari 286 pemda. Keseluruhan input data inovasi daerah tersebut mencakup 3 (tiga) kategorisasi bentuk inovasi, yakni:

a. Inovasi tata kelola pemerintahan daerah, berjumlah 698 inovasi atau 17,13\%;

b. Inovasi pelayanan publik, berjumlah 2.499 inovasi atau $61,33 \%$; dan

c. Inovasi daerah lainnya sesuai dengan Urusan Pemerintahan yang menjadi kewenangan daerah, berjumlah 878 inovasi atau $21,55 \%$.

$$
\text { Inovasi pelayanan publik }
$$

mendominasi jenis inovasi yang diajukan oleh pemda. Proporsinya mencapai $61,33 \%$ dari seluruh inovasi yang berhasil didata. Kondisi ini sangat dimaklumi karena inovasi pelayanan publik merupakan inovasi dalam penyediaan pelayanan kepada masyarakat yang meliputi: i) proses pemberian pelayanan barang/jasa publik; dan ii) inovasi jenis dan bentuk barang/jasa publik. Proporsi kedua adalah jenis inovasi daerah lainnya yang mencapai $21,55 \%$. 
Maknanya, pemda semakin menyadari pentingnya menyulut inovasi yang terkait dengan penyelenggaraan Urusan Pemerintahan yang menjadi kewenangan Pemerintah Daerah. Secara kontras, inovasi tata kelola Pemerintahan Daerah justru hanya mampu menyulut $17,13 \%$ dari total inovasi daerah. Padahal inovasi tata kelola pemerintahan daerah merupakan inovasi dalam pelaksanaan manajemen Pemerintahan Daerah yang meliputi: i) tata laksana internal dalam pelaksanaan fungsi manajemen; dan ii) pengelolaan unsur manajemen. Melalui tata kelola kepemerintahan yang baik (good governance) akan dicapai kinerja yang lebih baik.

Problemanya, daerah penginput didominasi oleh pemda yang berada di Pulau Jawa dan Pulau Sumatera, sehingga pemda yang berada di luar kedua pulau tersebut belum berkontribusi optimal dalam pelaksanaan inovasi daerah. Kondisi ini sangat mungkin terjadi karena perangkat daerah di Pemda Provinsi yang memiliki tugas dan fungsi di bidang penelitian dan pengembangan belum berperan sebagai fasilitator dan katalisator inovasi daerah.

\section{KESIMPULAN}

Pemda telah mengimplementasikan Roadmap Penguatan SIDa. Kondisi ini menjadi faktor pemicu berkembangnya inovasi daerah lebih dinamis dan variatif di berbagai pemda. Dinamikanya belum bersifat massif ke seluruh pemda, sehingga perlu didorong dengan melembagakan innovation hub.

Innovation hub menjadi strategi yang menstimulasi para aktor/kreator/inovator untuk melakukan inovasi daerah. Innovation hub berperan menjadi media kolaboratif yang mampu mengintegrasikan para pemangku kepentingan membentuk ekosistem inovasi daerah. Keberadaannya berkontribusi terhadap akselerasi inovasi, penciptaan innovator di daerah, dan membangun pemerintahan daerah yang lebih inovatifdinamis dengan kinerja tinggi.

Pada saatnya, innovation hub menjadi pemicu inovasi dan peubah pemda menjadi lebih dinamis, kreatif, adaptif, inovatif, produktif, futuristik, dan prospektif. Bila pemda memiliki semangat perubahan dan bertekat melembagakan innovation hub, niscaya terjadi peningkatan laju inovasi secara signifikan diikuti kualitas yang lebih baik dan memberi nilai tambah ekonomi.

\section{DAFTAR PUSTAKA}

Bank, T. W. (2011, October 10). Russia: Innovation and Technology Can Help Revitalize Economies in Emerging Europe and Central Asia. World Bank. Retrieved from https://www.worldbank.org/en/new s/pressrelease/2011/10/10/innovationtechnology-can-help-revitalizeeconomies-emerging-europecentral-asia

Indonesia, P. R. Peraturan Pemerintah Nomor 38 Tahun 2017 Tentang Inovasi Daerah, Pub. L. No. PP 38 Tahun 2017, Pemerintah Republik Indonesia (2017). Pemerintah Republik Indonesia.

Kotsemir, M. N., \& Meissner, D. (2013). Conceptualizing the Innovation Process - Trends and Outlook 
i. NAKHODA:

JURNAL

ILMU PEMERINTAHAN
NAKHODA: JURNAL ILMU PEMERINTAHAN

Edisi Januari-Juni Tahun 2020 Volume: 19 Nomor: 1

ISSN : 1829-5827 | E-ISSN : 2656-5277

DOI : https://doi.org/10.35967/jipn

https://nakhoda.ejournal.unri.ac.id/index.php/JIPN
(SCIENCE, TECHNOLOGY AND INNOVATION WP No. WP BRP 10/STI/2013). National Research University Higher School of Economics (HSE). https://doi.org/10.2139/ssrn.224978 2

Miles, M. B., \& Huberman, A. M. (1994). An Expanded Sourcebook Qualitative Data Analysis. Saga Publication (Second). California: Saga Publication Ltd. https://doi.org/10.1007/BF0275991 3

Neufeldt, V., \& Guralnik., D. B. (1991). Webster's New World Dictionary of American English (Third Coll). New York: Prentice Hall General Reference.

OECD. (2012). OECD Science, Technology and Industry Outlook 2012. Paris:

OECD. https://doi.org/10.1787/sti_outlook2012-en

Saksono, H. (2012). Ekonomi Kreatif: Talenta Baru Pemicu Daya Saing Daerah. Bina Praja, 4(2), 93-104.

Saksono, H. (2013). Ekonomi Biru: Solusi Pembangunan Daerah Berciri Kepulauan Studi Kasus Kabupaten Kepulauan Anambas. Jurnal Bina Praja, 05(01), 01-12. https://doi.org/10.21787/jbp.05.201
3.01-12

Saksono, H. (2016). Wajah Baru Otonomi Daerah: Status Kinerja Versus Kondisi Realistis di Wilayah Pemerintah Daerah Provinsi Kalimantan Selatan. Kebijakan Pembangunan, 11(2), 133-148.

Saksono, H. (2018). Kelurahan Silalas Sebagai Innovation Hub: strategi Kompetitif Pemerintah Kota Medan Melaluai Perangkat Kewilayahan. Inovasi, 15(2), 105-124.

Sidauruk, R., \& Saksono, H. (2018). Ekonomi Kreatif Sebagai Basis City Branding Menuju Kepariwisataan Terintegrasi Di Kawasan Danau Toba. Inovasi, 15(1), 83-104. https://doi.org/DOI:https://doi.org/1 0.33626/inovasi.v15i2.95

Tohidi, H., \& Jabbari, M. M. (2011). The important of Innovation and its Crucial Role in Growth, Survival and Success of Organizations. Procedia Technology, 1(1), 535538.

https://doi.org/10.1016/j.protcy.201 2.02.116

Youth, A. R. A. for C. and. What Is Collaboration? (2013). Camberra. https://doi.org/10.7551/mitpress/97 80262015813.003 .0001 